\title{
A comparative study and graphical analysis in designing and operation of Solar Thermal circular concentrator for enhancing efficiency of solar concentrating system
}

\author{
Mohan Kulkarni ${ }^{1,}{ }^{*}$, Sunil Dingre ${ }^{1}$ and Chandrakant Kulkarni ${ }^{2}$ \\ ${ }^{1}$ MIT School of Engineering, MIT ADT University, Pune, India \\ ${ }^{2}$ Zeal College of Engineering, Pune, India
}

\begin{abstract}
The present line concentrator system with constant concentration ratio exhibits rise in temperature of working media, however if the difference between outlet and inlet temperature of working media is large then they exhibit lower efficiency. Also the rate of fall of efficiency with increase in its temperature difference is high. To overcome this problem it is proposed to have a variable concentration ratio concentrator system. The variable concentration ratio is achieved by employing receiver consisting of the pipes having different diameters; with the larger diameter pipe at start followed by small diameter receiver. Thus, the concentrator system will have different diameter receivers offering variable concentration ratio system. This concept is confirmed with the help of G.O. Lof, Fester and Duffie Beck paper. The present paper describes above concept by graphical analysis carried out for the newly proposed circular line concentrator with variable concentration ratio. The results of superimposition of graphs leads to confirmation for the promisingly use of variable concentration ratio receivers for enhancing efficiency of solar concentrating system.
\end{abstract}

\section{Introduction}

Energy is the fundamental and moreover strategic tool to have a better quality life. The conventional energy resources are limited; also their excess utilization has led towards major environmental issues like global warming. [7] The solar energy can be harvested either by the technology referred as solar thermal or by photovoltaic. In case of photovoltaic technology the solar radiations are converted directly into electricity where in the solar thermal technology the heat from solar rays is extracted and is used for down line applications such as power generation, or material processing. In the present study attempts are made to design and develop effective solar concentrator system for midrange temperature yielding high efficiency with minimum heat loss.[8]Also, it is proposed to have the system with minimum change in a existing system, so that the existing system can be improved upon within less time and less expenses. In the present paper concentrator with variable diameter is proposed after the experimental study and graphical analysis of previous research work done by authors G.O. Lof, Fester and Duffie J.A., William A. Beckman [1] as a experimental output of these authors which concludes "Energy balance on a parabolic cylindrical solar collector" where they uses size of receiver 0.060 meter and 0.027 meter and 1.89 is the reflector aperture where they illustrate that for largest diameter receiver factor of intercept and heat losses are in excess amount.[1] B.S. Singh et al [2] studied and illustrates the relation between increment in the thermal losses with the developing area of aperture. Houtan Moaveni [3] has performed the experimental analyses, mathematical simulation and explained change of temperature in receiver is more sensible to the intercept factor of collector and also for the mirror reflectivity.

\section{Theoretical Considerations}

The figure.1 illustrates that as size of receiver tube decreases concentration ratio increases. Concentration ratio is represented by using lower limit curve where absorbed energy and thermal losses are equal [4]. Concentration ratio is nothing but the ratio of area of the collector aperture to the area of the surface of receiver. [5] A flux concentration ratio is defined as the ratio of the average energy flux on the receiver to that on the aperture, but generally there are substantial variations in energy flux over the surface of a receiver. Concentration ratio $(\mathrm{CR})$ is defined as the ratio of the collector aperture area to the surface area of the receiver. The area concentration ratio is

$$
\mathrm{C}=\mathrm{Aa} / \mathrm{Ar}
$$

* Corresponding author: mohan.kulkarni@mituniversity.edu.in 


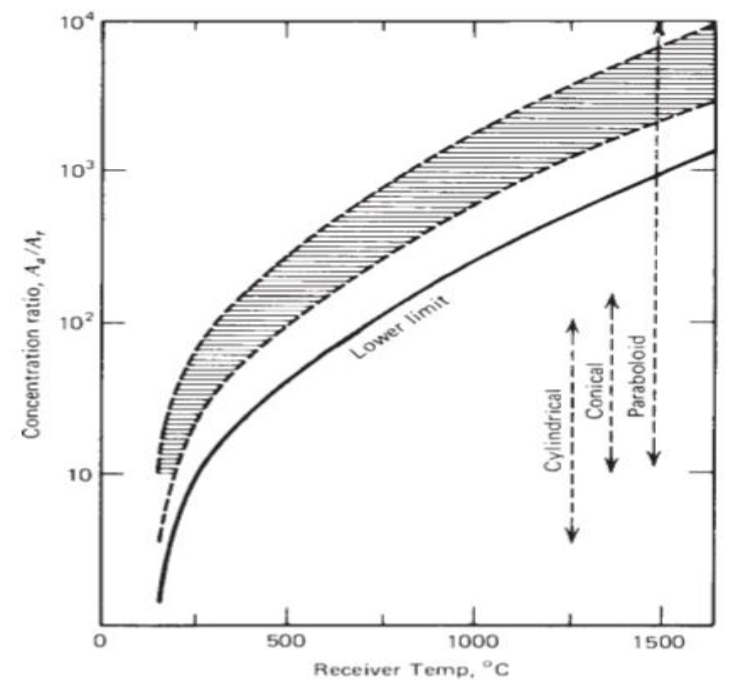

Figure1: Graph plotted between receiver temperature and concentration ratio [4]

Relation between Intercept factor and receiver diameter have evaluated by author G.O.G.LOF et al. In figure 2 graph plotted illustrates that $58 \%$ reflected radiations has been intercepted by the receiver having $0.027 \mathrm{~m}$ diameter. If there is a application of normal distribution which is shifted, interception would have been $57 \%$ and if symmetrical normal distribution is applied interception is $70 \%$.Observed values for $0.060 \mathrm{~m}$ receiver are $89 \%$, $95 \%$ and $90 \%$. Hence it illustrates that for a receivers having small diameters, actual distribution is transferred to theoretical focus while analysing the performance of collector which may lead to considerable error from symmetrical normal distribution. The experimental values are used to plot the graph by using theoretical tool named SoI trace software. This is a new optical modelling tool used to plot graph between receiver diameter and intercept factor. So during analysis of these experimental studies very minute observations of actual intercept factor are received related with shifted normal distribution of system. So for the referred system reflection of solar rays are in more amount for the receiver having large diameter in comparison with receiver having small diameter. However major losses are there for receiver having larger diameter [3].

The energy distribution of the incident rays for small and large sized receivers for full sized reflectors is shown in figure 3 and figure 4 which is a function of conditions compared as solar radiations, velocity of wind and ambient air temperature [3]. These illustrations show evident distribution of losses and direction logically to proceed further for performance improvement. In case of tubes having small diameter optical losses are more while at higher temperature for tubes having larger diameter optical and thermal losses are equally important. For reducing radiation loss and convection loss one can use transparent envelope but it may increases optical loss. By using desired coatings thermal loss could be reduced; however some of the imperfect absorbtivity could be generated for less than 095 solar radiations.

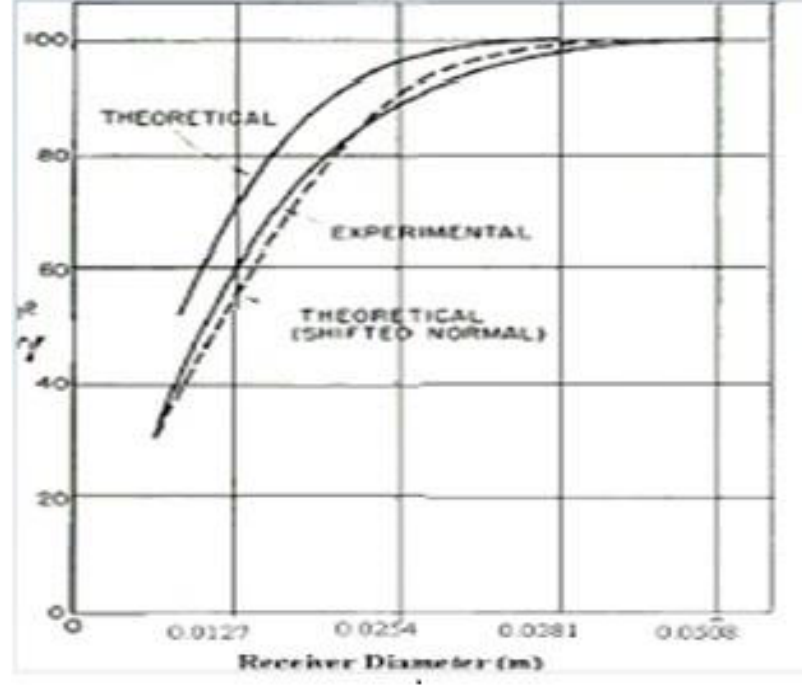

Figure 2: Graph plotted between Receiver diameter and intercept factor [1]

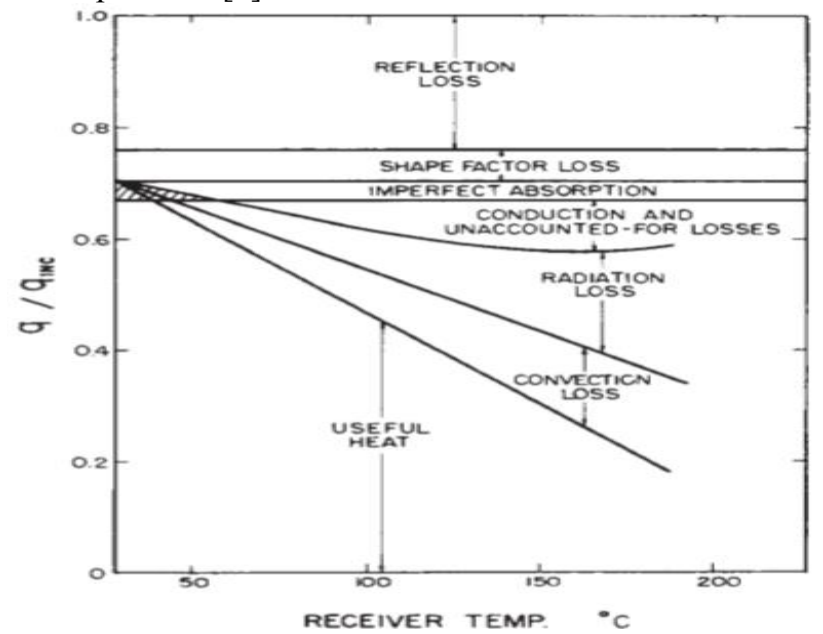

Figure 3: Graphical representation for $0.060 \mathrm{~m}$ receiver diameter and $1.89 \mathrm{~m}$ reflector aperture [3]

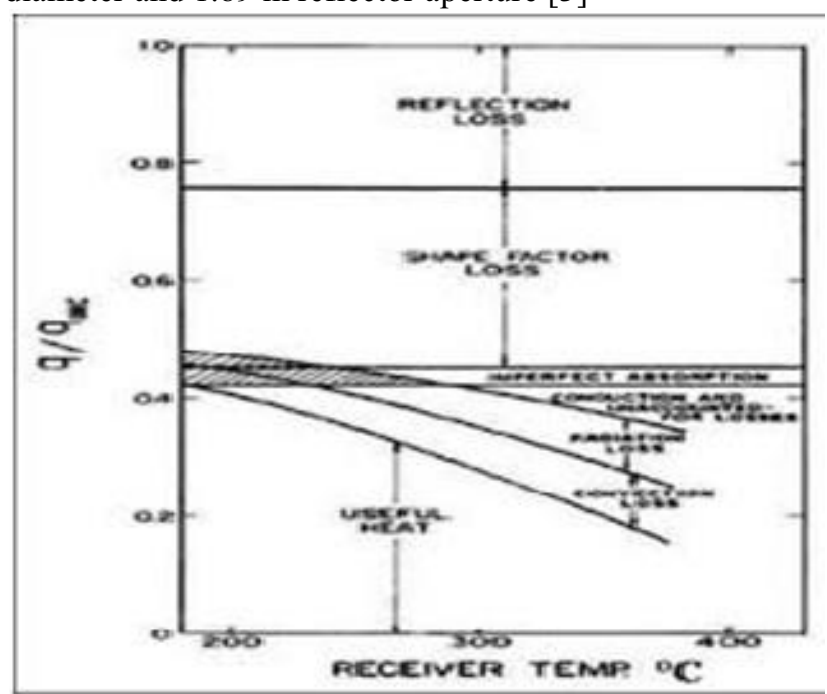

Figure4: Graphical representation for energy distribution incident for $1.89 \mathrm{~m}$ aperture reflector and $0.27 \mathrm{~m}$ receiver diameter.[3] 
The outcome of the above theoretical consideration illustrates that after employing a receiver with constant diameter convection and radiation heat losses are more and due to uniform diameter of receiver, the efficiency obtained is also low.

Figure 3 and figure 4 illustrates [1] the distribution of solar energy beam which are incident on collector and useful for effective heat gain and for finding losses for receiver having $0.060 \mathrm{~m}$ diameter and $0.027 \mathrm{~m}$ diameter. It shows evident magnitude for the losses. This graphical analysis shows that due to size variation in receiver diameter collector efficiency is affected.

Intercept factor is a receiver size function and leading to the increment in the energy intercepted by receiver. Where based on diameter of receiver there is a dependency of heat losing areas. For lower temperature, there is a major impact on thermal performance having large diameter. However as there is a major heat loss at high temperature, efficiency decreases. In another case where receiver having small diameter and concentration ratio is high and having less intercepted energy, there is low heat loss at higher temperature because of receiver is having less surface area. Hence for obtaining the good performance it is needed to optimize concentration ratio for varying temperature of fluid.

At the time of performance evaluation of solar concentrating system references are ready for receiver temperature. Where temperature of receiver $(\mathrm{Tr})$ and temperature of water (Tw) works parallel. It is illustrated in the (figure 5). In the proposed solar concentrating system, having design specifications as aperture of reflector is $0.6 \mathrm{~m}$ and its length $6 \mathrm{~m}$,with variable diameters without any glass cover receiver tubes with black coating. Experimental performance of this set up is shown in figure 5. For a given length difference between temperature of water (Tw) and temperature of receiver (Tr) is evident. The temperature difference between these $\mathrm{Tr}$ and $\mathrm{Tw}$ is less at starting and increases as length of receiver increases.[6] As in the proposed research work by author,for the preparation of experimental set up of solar thermal circular concentrator having dimension of reflector aperture $0.6 \mathrm{~m}$ and $6 \mathrm{~m}$ long in length,different diameter receiver without transparent cover is used in this set up. The difference between $\mathrm{Tr}$ and Tw is less at initial stage while as length increases difference increases due to variation in concentration ratio. Peak temperature difference between these Tw and $\mathrm{Tr}$ is obtained at the end was $142^{\circ} \mathrm{c}$

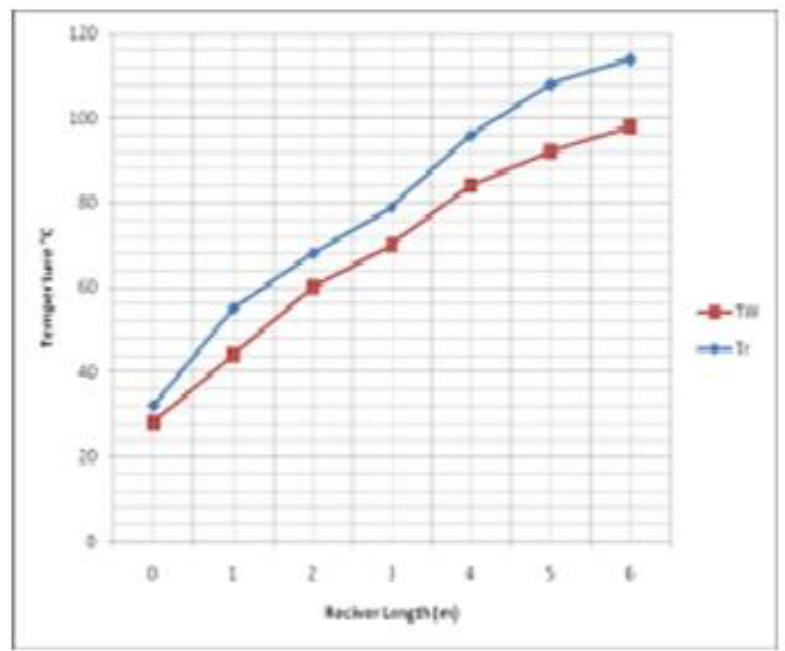

Figure 5: Graph showing difference between temperature of water and temperature of receiver

\section{Graphical collation of figure 3 and figure 4}

After the analysis of collation of figure 3 and figure 4, presented by Lof et al [3] author have drawn superimposed resultant and shown in figure 6.Receiver having $0.060 \mathrm{~m}$ diameter shows low performance up to temperature $170^{\circ} \mathrm{c}$ and receiver having $0.027 \mathrm{~m}$ diameter having higher temperature. Here these superimposed graphs are used to put forth new development of solar concentrating system with variable concentration ratio for enhancing the efficiency of concentrator system. In the present trends concentration ratio with constant receiver diameter is used which leads to low performance. Hence it proves that whenever there is a need of substantial difference between the exit and inlet, a solar concentrating system with variable concentrating ratio offers and may enhance the efficiency of concentrator system.

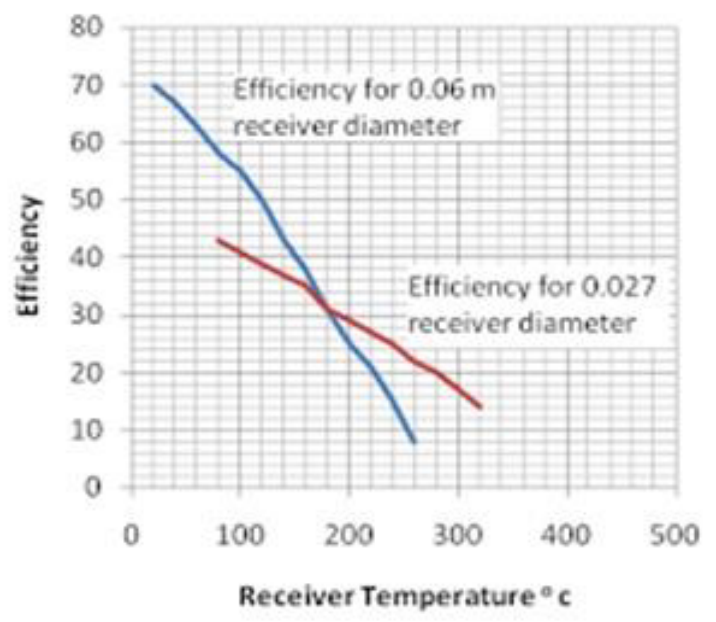

Figure 6: Graph showing superimposition of figure 3 and figure 4 [3] 


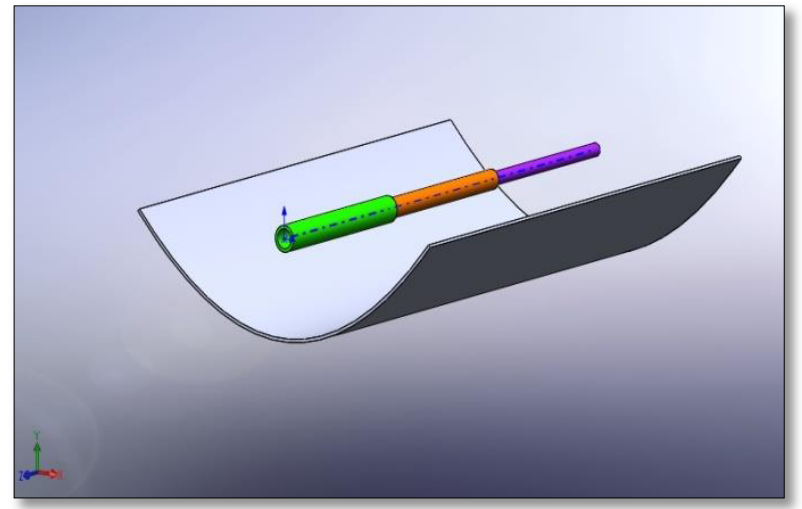

Figure 7: Variable concentration ratio receiver for constant aperture

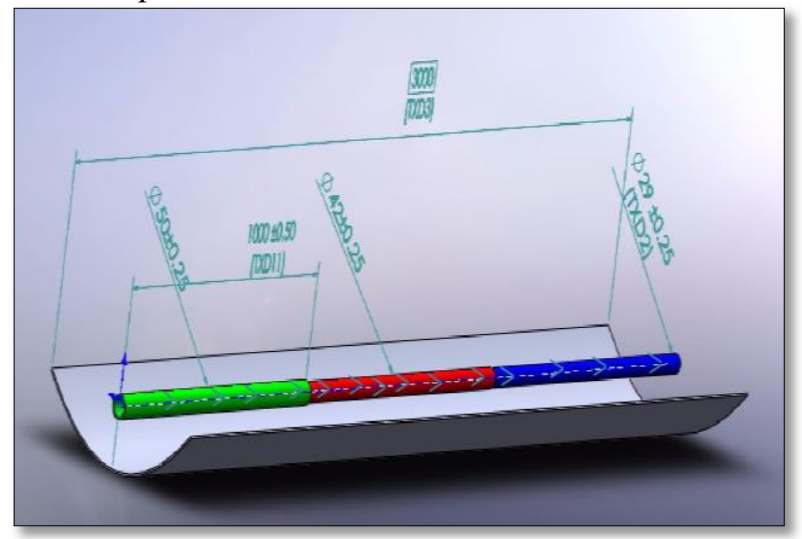

Figure 8: Showing flow and dimensions of panel for Variable concentration ratio receiver

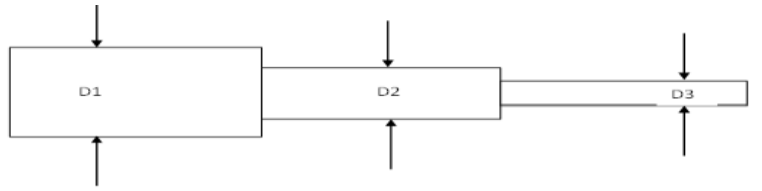

Figure 9: Variable concentration ratio receiver for constant aperture

\section{Conclusion}

As shown in Figure 6, intersection of the efficiency for the receiver having diameter $0.06 \mathrm{~m}$ and $0.027 \mathrm{~m}$ meets at one point. It illustrates that for large diameter, larger is the energy intercepted by receiver. While, as receiver diameter increases, heat loss also increases for that temperature of receiver. Hence for the improvement in efficiency there is a need to balance the energy intercepted and heat loss. It can be achieved by using larger diameter receiver at initial position where concentration ratio is lower and temperature of water is also low. Further portion of the concentrator where fluid temperature is higher, a high concentrator ratio can be used to reduce the loss of heat through reduction of area of the receiver tube (shown in Figure 7). As shown in Figure 8, authors have contributed for the preparation of experimental set up of solar thermal circular concentrator having dimension of reflector aperture $0.6 \mathrm{~m}$ and $6 \mathrm{~m}$ long in length. Different diameter receiver without transparent cover is used in this set up. Hence this experimental set up which is having receiver with variable concentration ratio is appropriate for the improvement in efficiency of solar thermal circular concentrator. In the experimental set up used by researchers, $0.027 \mathrm{~m}$ receiver diameter receiver offers higher efficiency as compared with $0.06 \mathrm{~m}$ diameter. Hence authors have drawn the conclusion to use a receiver having stepped receiver with diameter $0.06 \mathrm{~m}$ upto $170^{\circ} \mathrm{c}$ and then $0.027 \mathrm{~m}$ can be used to adopt higher efficiency. Keeping the same theme authors have proposed to use a multistepped receiver with variable concentration ratio based on the range of temperature and fluid for the system in reference.

\section{Appellation}

\begin{tabular}{|l|l|l|l|}
\hline $\mathrm{A}_{\mathrm{a}}$ & $\begin{array}{l}\text { Area of aperature } \\
(\mathrm{m} 2)\end{array}$ & $\mathrm{q}_{\mathrm{u}}$ & Heat gain rate $(\mathrm{w})$ \\
\hline $\mathrm{A}_{\mathrm{r}}$ & Receiver area $(\mathrm{m} 2)$ & $\mathrm{T}_{\mathrm{r}}$ & $\begin{array}{l}\text { Temp.of receiver } \\
\text { surface }\left({ }^{0} \mathrm{C}\right)\end{array}$ \\
\hline $\boldsymbol{r}$ & Factor of intercept & $\mathrm{T}_{\mathrm{w}}$ & $\begin{array}{l}\text { Water Temperature } \\
\left({ }^{0} \mathrm{C}\right)\end{array}$ \\
\hline
\end{tabular}

\section{References}

[1] G.O.G.LOF "Energy balance on a parabolic cylindrical solar collector" ASME PP.24-32, Jan 1962

[2] Balbir Singh Mahinder Singh, Fauziah Sulaiman, "Designing A Solar Thermal Cylindrical Parabolic trough Concentrator By Simulation "International Rio3 Congress, World Climate and Energy Event, pp. 15,December 2003

[3] Houtan Moaveni, "Numerical Analysis and Experimental Study in Design and Operation of Three Solar Parabolic Thermal Power Plants", powering, pp.12-14, April 2007

[4] John A. Duffie, William A. Beckman, "Solar Engineering of Thermal Processes", John Wiley and Sons INC, pp. 324-373, 2006.

[5] Sukhatme S., "Solar Energy, Principles of thermal collection and storage," Tata McGraw Hill-Publication, pp.71-257, 2010.

[6] Enhancing Performance of Solar Line Concentrator System Using Variable Concentration Ratio, Science Direct, Materials Today: Proceedings 4 (2017) 75337545

[7] William Stine and Raymond W Harrington,(1985) A Book on "Solar Energy Fundamentals and Design", John Wiley and sons.

[8] Brain Norton,( 2014)A Book on "Harnessing Solar Heat", 2nd Edition, Springer 